\title{
Advances in the surgical management of gastric and gastroesophageal junction cancer
}

\author{
Raja R. Narayan, George A. Poultsides \\ Department of Surgery, Stanford University School of Medicine, Stanford, CA, USA \\ Contributions: (I) Conception and design: All authors; (II) Administrative support: All authors; (III) Provision of study materials or patients: None; \\ (IV) Collection and assembly of data: All authors; (V) Data analysis and interpretation: All authors; (VI) Manuscript writing: All authors; (VII) Final \\ approval of manuscript: All authors. \\ Correspondence to: George A. Poultsides, MD, MS. Chief, Section of Surgical Oncology, Associate Professor of Surgery, Department of Surgery, \\ Stanford University, 300 Pasteur Dr, Room H3591, Stanford, CA 94305, USA. Email: gpoultsides@stanford.edu.
}

\begin{abstract}
Since Theodore Billroth and Cesar Roux perfected the methods of post-gastrectomy reconstruction in the late $19^{\text {th }}$ century, surgical management of gastric and gastroesophageal cancer has made incremental progress. The majority of patients with localized disease are treated with perioperative combination chemotherapy or neoadjuvant chemoradiation. Staging laparoscopy before initiation of treatment or before surgical resection has improved staging accuracy and can drastically inform treatment decisions. The longstanding and contentious debate on the optimal extent of lymph node dissection for gastric cancer appears to have settled in favor of D2 dissection with the recently published 15-year followup of the Dutch randomized trial. Minimally invasive gastric and gastroesophageal resections are performed routinely in most centers affording faster recovery and equivalent oncologic outcomes. Pylorus-preserving distal (central) gastrectomy has emerged as a less invasive, function-preserving option for T1N0 middlethird gastric cancers, while randomized data on its oncologic adequacy are pending. Multi-visceral resections and cytoreductive surgery with hyperthermic intraperitoneal chemotherapy has been utilized selectively for patients with locally advanced tumors who have demonstrated disease control on preoperative chemotherapy. This review summarizes the current standard of surgical care for gastroesophageal junction and gastric cancer as well as highlights recent and upcoming advances to the field.
\end{abstract}

Keywords: Gastrectomy; gastric adenocarcinoma; gastroesophageal junction cancer; minimally invasive surgery

Received: 02 January, 2020; Accepted: 15 January, 2020; Published: 05 January 2021.

doi: $10.21037 / \operatorname{tgh} .2020 .02 .06$

View this article at: http://dx.doi.org/10.21037/tgh.2020.02.06

\section{Introduction}

The incidence of gastric cancer has been declining over the past several decades but the incidence of gastroesophageal junction cancer has been rising (1). Surgery is the only potentially curative option for gastric and gastroesophageal junction adenocarcinoma but the operative strategy of choice depends on multiple tumor-related factors. Moreover, the broader oncologic surgical strategy has also matured in recent years to optimize tumor clearance, pathologic staging, and postoperative functional status. This review aims to summarize existing strategies and novel options for the surgical therapy of gastric and gastroesophageal junction cancer.

\section{Staging laparoscopy}

Historically, diagnostic laparoscopy has been underutilized in the staging of gastric cancer (2). A SEER database study of all resected gastric cancer patients from 2004-2013 found that only $13 \%(n=733 / 5,610)$ underwent staging laparoscopy (2). Despite this, a quarter of gastric cancer patients undergoing staging laparoscopy can have positive peritoneal cytology (3). Poor survival following primary tumor resection in the context of positive peritoneal 


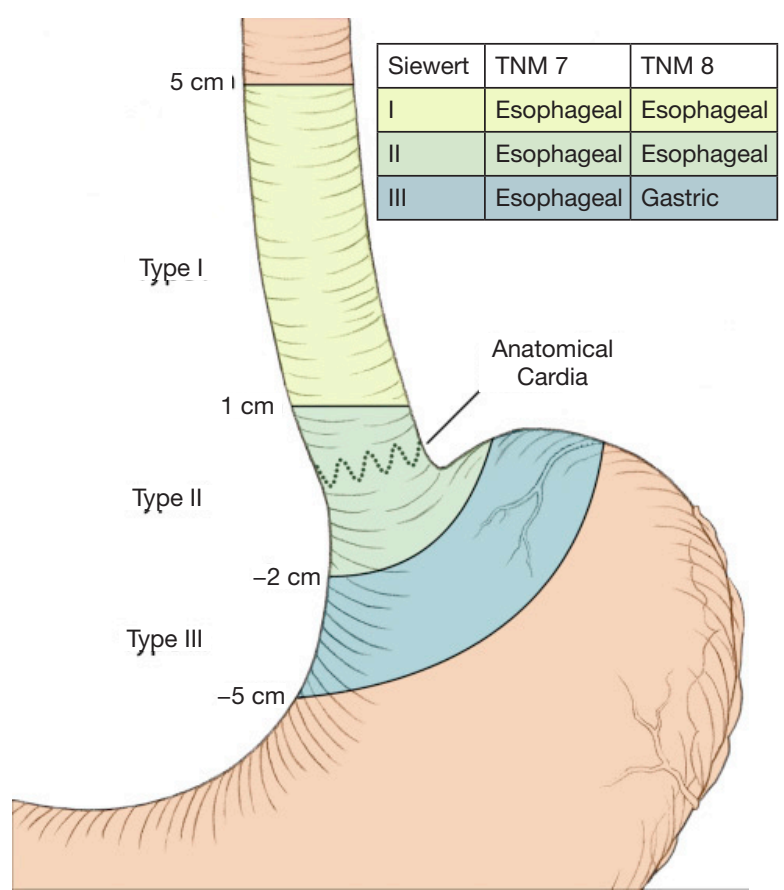

Figure 1 Siewert classification of gastroesophageal cancer and management strategy per the seventh and eighth editions of the AJCC TNM staging system. From Mazer and Poultsides, Surg Clin North Am 2019;99:457-69; with permission.

cytology has led most centers to abandon gastrectomy upon detection of malignant cells in peritoneal washings, however the utility of cytoreductive surgery and hyperthermic intraperitoneal chemotherapy for this patient population is currently under investigation, as noted below (3). Earlier reports on the detection of peritoneal disease from staging laparoscopy summarized in a systematic review and metaanalysis of 240 patients reported a sensitivity and specificity of $85 \%$ and $100 \%$, respectively (4). A more recent report of 214 gastric cancer patients with known carcinomatosis challenged the utility of peritoneal washings at the time of staging laparoscopy reporting that only 77 (36\%) were found to have malignant cells on examination of peritoneal cytology resulting in a sensitivity of only 64\% (5). To clarify this discrepancy, two trials are now underway prospectively investigating the utility of staging laparoscopy with peritoneal washings in resectable locally advanced gastric adenocarcinoma patients $(6,7)$. At our institution, in order to optimize the yield of the procedure, we utilize staging laparoscopy selectively at the time of gastrectomy for patients with poorly differentiated histology or locally advanced disease ( $\geq$ cT2 or clinically node-positive), and before initiation of any treatment for patients with questionable peritoneal lesions on imaging.

\section{Selection of surgical strategy}

\section{Gastroesophageal junction cancer}

For gastroesophageal junction (GEJ) tumors, the surgical management and overall oncologic strategy depends on where the tumor epicenter resides relative to the most proximal end of the gastric folds, as specified by the Siewert classification system (Figure 1) (8,9). Previously, all GEJ tumors were recommended to be managed similar to esophageal cancer. New to the 8th edition of the American Joint Committee on Cancer (AJCC), some type II and most type III GEJ tumors are now recommended to be managed similarly to gastric cancer (10).

Siewert type I tumors are located between 1 and $5 \mathrm{~cm}$ proximal to the GEJ and are considered to have the biology of esophageal adenocarcinoma. Accordingly, type I tumors are managed with esophagectomy and mediastinal lymph node dissection $(11,12)$. The most common surgical methods to mobilize the esophagus for esophagectomy include the transthoracic or transhiatal approaches (9). Transthoracic esophagectomy is approached from a right thoracotomy and laparotomy, as done for an Ivor Lewis or Tanner-Lewis esophagectomy, to sharply perform a lymphadenectomy in both the mediastinum and abdomen. A gastric conduit is constructed and delivered into the posterior mediastinum where an anastomosis is constructed at the level of the azygous vein. The anastomosis can be constructed in the neck using a left cervical incision as well, as is done in the McKeown or three-field approach. The risk for leak following the thoracic anastomosis is notably less than with a cervical anastomosis, however, anastomoses in the thorax are associated with a higher reoperation rate if a postoperative anastomotic leak occurs-as is the case in 4-10\% (13). Greater perioperative morbidity and mortality have overall been associated with thoracotomy $(14,15)$.

The transhiatal esophagectomy is approached from the esophageal hiatus and a left cervical incision to bluntly mobilize the thoracic esophagus. This blunt approach enables a limited periesophageal and mediastinal lymphadenectomy and carries with it the risk for airway and vascular injury. Relative to the thoracic anastomosis, a cervical anastomosis is associated with a higher rate of anastomotic leak-12\% compared to $5 \%$-however the morbidity of a cervical leak is lower (13). On the other hand, 
pharyngeal reflux, nocturnal aspiration, and prolonged swallowing dysfunction with hoarseness postoperatively are attributable to the increased risk of recurrent laryngeal nerve damage with the transhiatal or cervical approach (16).

Another approach for stage I tumors includes minimally invasive esophagogastrectomy which involves performing the resection using combined thoracoscopic and laparoscopic approaches to create the esophagogastric anastomosis in the chest or neck. The transhiatal approach is also feasible with laparoscopy. When comparing the minimally invasive approach to open, no difference in survival has been noted-however, a phase III trial is underway to investigate this (17).

Siewert type II GEJ tumors derive from the true gastric cardia and can be challenging to define and treat, especially if straddling multiple zones. Given the absence of high-quality trials designating the GEJ as its own region, consensus on the best surgical strategy can be lacking in many cases. Resection of type II GEJ tumors can be achieved by total gastrectomy and distal esophagectomy (with either a left thoracoabdominal or abdominal approach) as well as esophagectomy using a transhiatal or transthoracic approach.

The majority of GEJ adenocarcinoma cases are Siewert type III which bear the worst prognosis (18). Given the recent re-classification of type III GEJ tumors as gastric cancer, the surgical options include total gastrectomy and proximal gastrectomy. A historical landmark study from 1980 set the precedent that total gastrectomy was the preferred operation describing a retrospective review of 101 patients that had longer negative margins, more lymph nodes sampled, and fewer local recurrences with this procedure compared to proximal gastrectomy, although survival did not significantly differ (19). The morbidity associated with total gastrectomy (weight loss, anemia, failure to thrive) has led some groups to reopen the investigation into whether proximal gastrectomy could offer comparable oncologic outcomes in addition to a better quality of life $(20,21)$. Patients undergoing proximal gastrectomy can theoretically have better functional outcomes due to preservation of the gastric reservoir and pylorus as well as intact vagal stimulation and hormone secretion (20). A meta-analysis of a randomized controlled trial and seven retrospective cohort studies pooling 1,077 patients showed no difference in 5 -year survival between patients undergoing total and proximal gastrectomy, however, recurrence risk was lower in the former. In addition, proximal gastrectomy patients had greater risk for morbidity overall as well as specifically alkaline reflux and anastomotic stenosis (22). Moreover, a recently published Italian multi- center study noted that although patients undergoing proximal gastrectomy had shorter resection margins and fewer sampled lymph nodes, survival did not significantly differ from patients undergoing total gastrectomy (23). Following gastrectomy, the method of reconstruction varies as well ranging from gastric pull-up, Billroth II, Roux-en-Y reconstruction, and jejunal interposition grafts $(24,25)$. The authors' institution most commonly selects total gastrectomy with Roux-en-Y reconstruction for proximal gastric cancer (and type III GEJ adenocarcinoma).

Two key oncologic goals at the time of resection of GEJ tumors include obtaining long proximal negative margins and sufficient lymph node samples for staging. More important than tumor histology or surgical strategy, achieving an $\mathrm{R} 0$ resection remains the most critical factor to predict survival (9). Multiple retrospective studies have shown that achieving macroscopic clearance greater than $5-6 \mathrm{~cm}$ is associated with negative resection margins and significantly longer survival $(26,27)$. Indeed, these reports found that patients undergoing esophagectomy obtained significantly longer proximal margins than those undergoing gastrectomy, however, more recent work found no association between the rate of obtaining negative margins and the use of esophagectomy over total gastrectomy (28). Furthermore, achieving longer proximal margins has not been shown to be associated with survival or local recurrence (29). Therefore, routine esophagectomy to obtain a longer proximal margin is not warranted. Selection of the optimal operative strategy should depend on the characteristics of the tumor, where its epicenter extends into, and the experience of the surgeon. After achieving negative margins, the presence of lymph node metastases is strongly prognostic for survival (30), however, the ideal number and location of lymph nodes to sample remains controversial. The AJCC considers 15 lymph nodes sufficient for pathologic staging of gastric cancer postoperatively, but this is not well-defined for esophageal or GEJ tumors. One database study reported that sampling 21 or more lymph nodes was associated with better survival, however, this study was chiefly limited by the lack of data regarding the pathologic evaluation of the lymph nodes, their location, and margin status (31).

\section{Gastric cancer}

\section{Total gastrectomy}

The surgical management of gastric adenocarcinoma is also dependent on where the epicenter of the tumor resides, the extent of stomach involvement, the histologic subtype, 


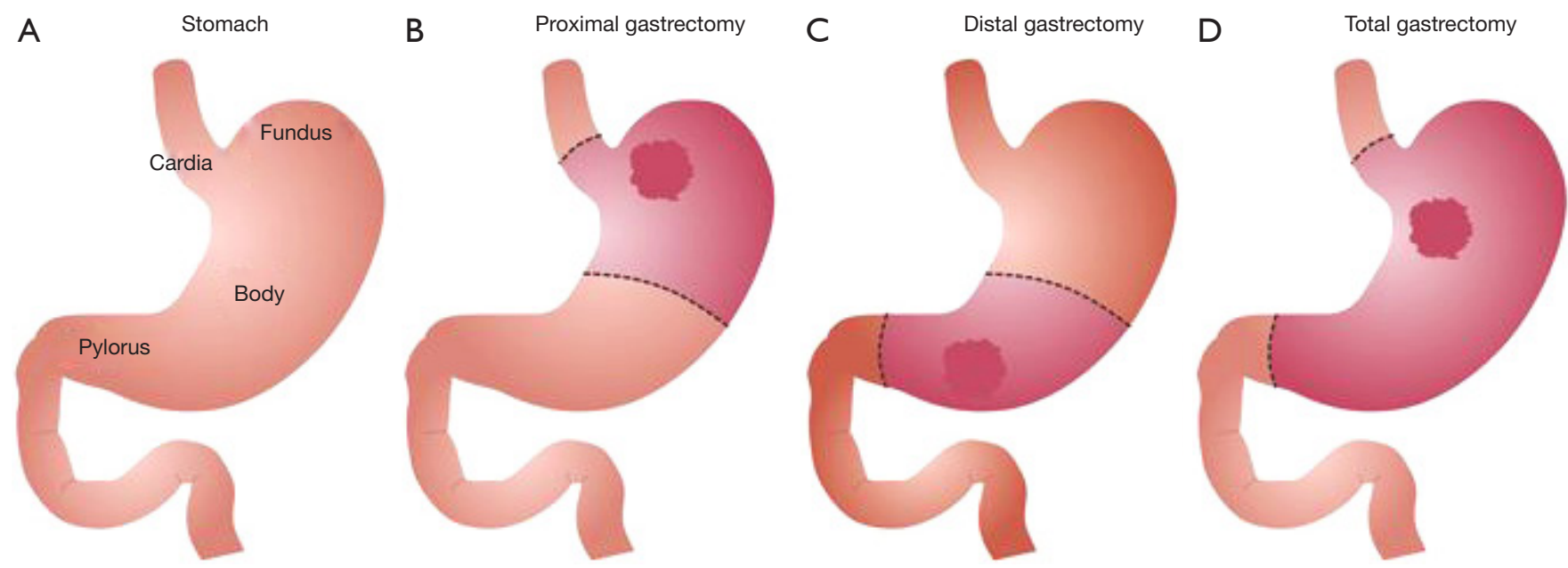

Figure 2 Surgical Options for Gastrectomy. From Stange and Weitz. Methods of Reconstruction—BI, BII, Roux-en-Y, Jejunal Interposition, Proximal Gastrectomy and Pouch Reconstruction. In: Strong V. editor. Gastric Cancer. Springer, Cham; with permission. 2015.

and the genomic etiology (Figure 2) (32). Total gastrectomy is recommended for most tumors involving at least the majority of the proximal stomach. Additionally, distal tumors spanning most of the lesser or greater curvature would require total gastrectomy due to the inability to obtain a negative proximal margin. Large or expansive tumors preventing resection with $4-6 \mathrm{~cm}$ of macroscopically negative margins would warrant total gastrectomy as well. Furthermore, signet ring cell histology can indicate disease prone to diffuse submucosal seeding rendering an R0 resection challenging without total gastrectomy (33). Lastly, inactivating germline mutations of the $\mathrm{CDH} 1$ gene, which expresses E-cadherin, are known to be risk factors for multifocal gastric cancer and thus warrant prophylactic total gastrectomy (34).

With the patient in supine position, an upper midline incision spanning the xiphoid to the umbilicus is generally the approach of choice. At times, a left thoracoabdominal incision can be performed beginning from the seventh intercostal space on the left anterolateral side extending to the upper midline when operating for a bulky cardia or fundus tumor that extends toward the esophagus. This also enables exposure of the supradiaphragmatic distal esophagus to the level of the inferior pulmonary ligament. Use of a double-lumen endotracheal tube to deflate the left lung for such proximal dissection is advised as well. Upon entry to the abdomen, a thorough search for metastatic disease is undertaken with attention to the liver, peritoneum, hepatoduodenal ligament, or root of the mesentery. Discovery of metastases therein would preclude gastrectomy. For patients with high risk or locally advanced tumors, this should be done with diagnostic laparoscopy. With the operating room bed tilted to position the patient in the right semi-lateral decubitus position, the left triangular ligament of the liver is divided to mobilize the left lateral segment to the right and superior with the goal of exposing the GEJ. The greater omentum is divided from the transverse colon and epiploic appendages. The right gastroepiploic vessels should next be taken at their origin from the gastroduodenal artery and gastrocolic trunk of the superior mesenteric vein. Short gastric vessels should be taken close to the spleen followed by division of the left gastroepiploic artery close to where it originates off the splenic artery. The right gastric artery is next ligated before the duodenum is divided, generally with a linear stapler. The gastrohepatic ligament can next be divided close to the liver with care taken not to damage a replaced or accessory left hepatic artery tracking through this region. The stomach is then retracted superiorly to aid in dissection of lymph nodes near the porta, hepatic artery, and celiac trunk by thinning structures lateral to the left hepatic artery, back to the celiac trunk, then posterior to the common hepatic artery before dividing the left gastric artery near its origin off the celiac trunk. The phrenoesophageal ligament is then divided enabling circumferential dissection of the distal esophagus, excision of the paracardial lymph nodes, and finally division of the distal esophagus.

The preferred reconstruction method after total gastrectomy is a Roux-en-Y esophagojejunostomy. Ideally, a 40-60 cm Roux limb should be created from the 
jejunojejunostomy to minimize alkaline reflux proximal to the anastomosis. The esophagojejunostomy can be performed with a hand-sewn technique of single-layer interrupted or running absorbable suture. Additionally, an EEA circular stapler can be used where an anvil stapler is placed into the distal end of the esophagus and closed with purse-string suture over the anvil. The anvil can be placed using an orogastric tube delivered by the anesthesiologist as well. In the early postoperative period, the anastomosis should be kept defunctionalized (only saliva is permitted to pass) to allow for optimal healing. Multiple prospective trials (35-37), meta-analyses $(38,39)$, and multiinstitutional studies (40) have demonstrated no benefit with the routine use of drains following total gastrectomy. At our institution, drain placement is only considered when extra-visceral extension involves the pancreatic capsule necessitating pancreatectomy for oncologic clearance. Feeding jejunostomy placement, however, is a common practice to allow for extended enteral feeding for those with risk factors for esophagogastric leak or preoperative weight loss. More recent work has raised the question of whether routine feeding jejunostomy tube placement is beneficial for all given the elevated risk for infectious complications without increased receipt of adjuvant therapy $(41,42)$. Postoperatively, our practice has been to perform a fluoroscopic upper GI study by the fifth day after surgery to assess for an anastomotic leak before initiating oral intake.

\section{Distal gastrectomy}

For tumors amenable to distal over total gastrectomy, better safety and long-term functional profiles are noted especially for older or malnourished patients with multiple comorbidities (32). When wide margins $(4-6 \mathrm{~cm})$ can be obtained for tumors near the gastric outlet, distal gastrectomy is the operation of choice. Compared to a total gastrectomy, it is critical to save some short gastric vessels when performing a distal gastrectomy. Blood flow to the residual stomach can entirely depend on these short gastric vessels. For staging purposes, it is critical to dissect out the cephalad branch of the left gastric artery diverging high along the lesser curvature to obtain adjacent lymph nodes including those near the distal $2-3 \mathrm{~cm}$ of the esophagus.

Following resection, two common modalities for reconstruction are Billroth II or Roux-en-Y gastrojejunostomy. In most, a Billroth I is not feasible because the fixed duodenum cannot typically reach the gastric stump. With a Billroth II, the jejunal limb is brought up either antecolic to the transverse colon to meet the gastric stump or retrocolic through a defect in the transverse mesocolon. Generally, a proximal loop of jejunum located just beyond the ligament of Treitz can be brought up to form an anastomosis without tension or angulation. A long afferent limb-conducting pancreatobiliary secretions-should be avoided to reduce the risk of kinking or occlusion which could result in afferent loop syndrome. Despite best efforts, Billroth II anastomoses are commonly fraught with alkaline reflux gastritis. Additionally, malabsorption of fat-soluble vitamins can be associated with loss of duodenal continuity. Our practice has been to reconstruct with a Roux-en-Y gastrojejunostomy (RYGJ) using a Roux limb of 40-50 cm to reduce the risk of alkaline reflux (43-45). When comparing the reconstruction methods, better long-term outcomes have been noted with RYGJ including reduced bile reflux or esophagitis, better quality of life, and fewer abnormal findings on upper endoscopy up to 21 years after surgery (46-48).

\section{Pylorus-preserving distal gastrectomy}

Some centers have moved to perform the pylorus-preserving distal gastrectomy (PPDG) with gastro-gastrostomy noting the associated lower risk for bile reflux, dumping syndrome, gallstone formation, and weight loss (49-51). Relative to the classic distal gastrectomy, PPDG is technically more challenging given the need to preserve infrapyloric vessels and the hepatic branch of the vagus nerve. Preservation of the infrapyloric vessels, however, has raised the question of whether an oncologically adequate lymph node dissection can be achieved with PPDG (52). Given this concern and a report showing relatively fewer lymph nodes obtained from the infrapyloric and suprapyloric nodal stations with PPDG (53), Japanese guidelines have supported PPDG only for cT1N0M0 gastric cancer arising in the middle of the stomach when a macroscopically negative $4 \mathrm{~cm}$ distal margin could be obtained (54). To further investigate the utility of PPDG versus distal gastrectomy with the laparoscopic-assisted approach, an ongoing Korean multicenter randomized controlled trial (KLASS-04) will compare postoperative outcomes for resected patients with T1N0 cancer arising in the middle-third of the stomach.

\section{Proximal gastrectomy}

For gastric cancer in the upper-third of the stomach, proximal gastrectomy can be performed to preserve the physiologic function of the distal stomach and pylorus. For patients with early gastric cancer (cT1N0M0), American and Japanese guidelines support proximal gastrectomy $(54,55)$. Recent reports comparing outcomes of proximal 
with total gastrectomy have noted short-term pitfalls with long-term benefits. Two propensity-score matched studies found that patients undergoing proximal gastrectomy had shorter operative time and similar operative bleeding as well as shorter resection margins and fewer lymph nodes retrieved $(23,56)$. Proximal gastrectomy led to more incidents of reflux esophagitis and anastomotic stricture compared to total gastrectomy, but 5-year overall survival did not differ nor was the selected resection type an independent prognostic factor for survival on multivariate analysis. Moreover, higher total protein, serum albumin, and lean body mass could be maintained with proximal compared to total gastrectomy. Indeed, a meta-analysis of 18 studies pooling over 2,000 patients with early gastric cancer noted shorter operative time and less intraoperative blood loss as well as no difference in overall survival with proximal gastrectomy compared to total gastrectomy (57). Expectedly, more cases of anastomotic stricture and reflux esophagitis were noted in patients undergoing proximal gastrectomy as well.

Several methods for reconstruction have been described following proximal gastrectomy including esophagogastrostomy, jejunal interposition, and double tract reconstruction. Esophagogastrostomy is the most common reconstruction after proximal gastrectomy, preferred by half of the 145 Japanese institutions questioned in one survey, due to its association with lower blood loss and faster operative time (58). Compared to esophagogastric end-to-end anastomosis and posterior gastric wall endto-side esophagogastrostomy, anterior gastric wall endto-side esophagogastrostomy is the method of choice due to its association with fewer cases of reflux, improved meal intake, and increased postoperative weight. The main pitfall of esophagogastrostomy is the associated increased risk for bile reflux relative to the other methods of reconstruction (59). A jejunal interposition is generally performed with a $10-20 \mathrm{~cm}$ jejunal limb delivered antecolic or retrocolic to form an end-to-side esophagojejunal anastomosis and an end-to-side or side-to-side gastrojejunostomy with the anterior gastric wall (60). A 25-35 cm jejunal limb can also be reversed and brought retrocolic to construct a U-shaped $10-15 \mathrm{~cm}$ jejunal pouch that is connected in similar fashion. Lastly, a double tract reconstruction involves creation of a Roux-en-Y esophagojejunostomy and a side-to-side gastrojejunostomy $10 \mathrm{~cm}$ below with an end-to-side jejunojejunostomy $20 \mathrm{~cm}$ distal to the gastrojejunostomy. The preference at our institution is to perform an esophagogastrostomy reconstruction following proximal gastrectomy.

\section{Extent of lymphadenectomy}

At the time of gastrectomy, a comprehensive lymphadenectomy is critical for pathologic staging. Historically, three types of lymphadenectomy performed with gastrectomy have been described (Figure 3) (32). D1 lymphadenectomy involves dissection circumferentially along the stomach to retrieve nodes from stations 1-6. D2 lymphadenectomy includes lymph nodes retrieved with a D1 dissection as well as retrieval of nodes along the celiac trunk and its branches (common hepatic artery, left gastric artery, and splenic artery) comprising stations 7-11. Finally, a D3 lymphadenectomy includes additional lymph nodes along the portal tract, hepatic artery, and adjacent to the aorta (stations 12-16). Multiple retrospective reports have noted an association between improved survival and increased number of lymph nodes retrieved in the gastrectomy specimen (61-65). Early trials showed less morbidity and mortality with D1 dissection, however long-term follow up has revealed better disease-specific survival with D2 lymphadenectomy (Table 1) (66-71). D2 lymphadenectomy has classically been considered the gold standard in Asia given remarkable long-term survival and perioperative mortality rate less than 1\% (72). Traction for this procedure came slowly elsewhere in part due to two prospective randomized trials out of the United Kingdom and the Netherlands in the 1990s that did not show a survival advantage with performing D2 over D1 lymphadenectomy $(67,68,73,74)$. Perioperative mortality with D2 lymphadenectomy (13\% and 10\%) was also notably greater than that associated with D1 lymphadenectomy (6.5\% and $4 \%$ ), however, this was largely attributed to the routine use of distal pancreatectomy and splenectomy for D2 dissections. A more recent report from the Italian Gastric Cancer Study Group noted that Western surgeons could perform D2 dissections with acceptably low mortality (2.2\%) (70). Moreover, Japanese surgeons have come to embrace pancreas-preserving D2 lymphadenectomy as equally effective as the pancreas-sacrificing analogues (75). Finally, a recent update to the Dutch D1D2 trial after a median follow-up of 15 years revealed that D2 lymphadenectomy was associated with longer diseasespecific survival compared to D1 (lower disease-related death rate, $37 \%$ vs. $48 \%$, respectively) settling the debate in favor of D2 lymphadenectomy (69). Trials investigating D3 lymphadenectomy have found a survival advantage compared to D1 (76), however no survival benefit 


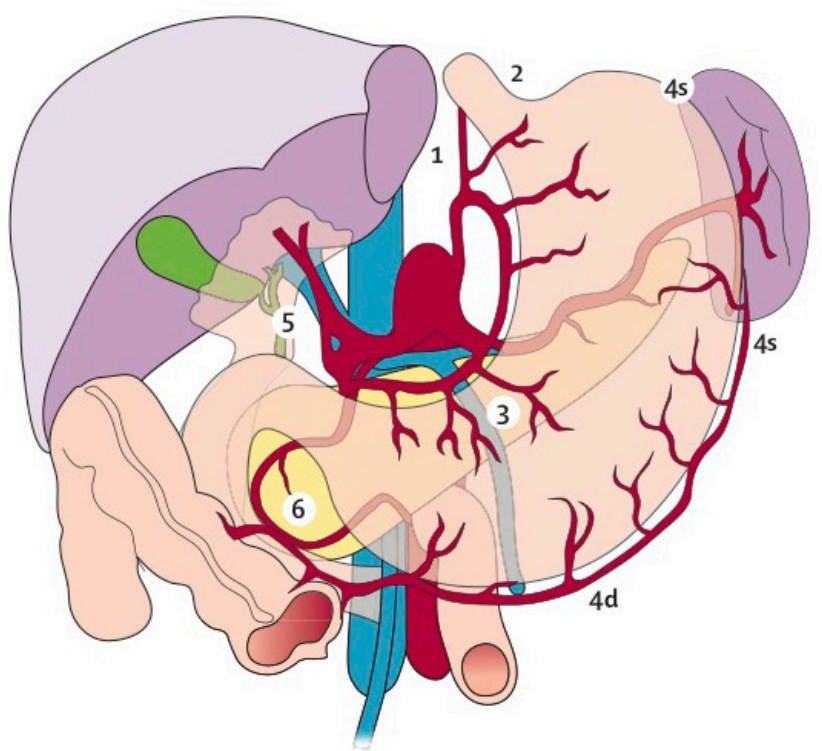

D1 Lymph nodes (perigastric)

1 Right cardiac nodes

$\begin{array}{llll}2 & \text { Left cardiac nodes } & 7 & \text { Nodes along root left gastric } \\ 3 & \text { Nodes along the lesser curvature } & \text { arteryg }\end{array}$

4d Lymph nodes along the short gastric 8 Nodes along common hepatic and the left gastroepiploic vessels

4s Lymph nodes along the right

gastroepiploic vessels

5 Suprapyloric nodes

6 Infrapyloric nodes

\begin{abstract}
D2 Lymph nodes (branches coeliac axis) arteryg

9 Nodes around coeliac axis

10 Nodes at splenic hilum

11 Nodes along splenic artery
\end{abstract}

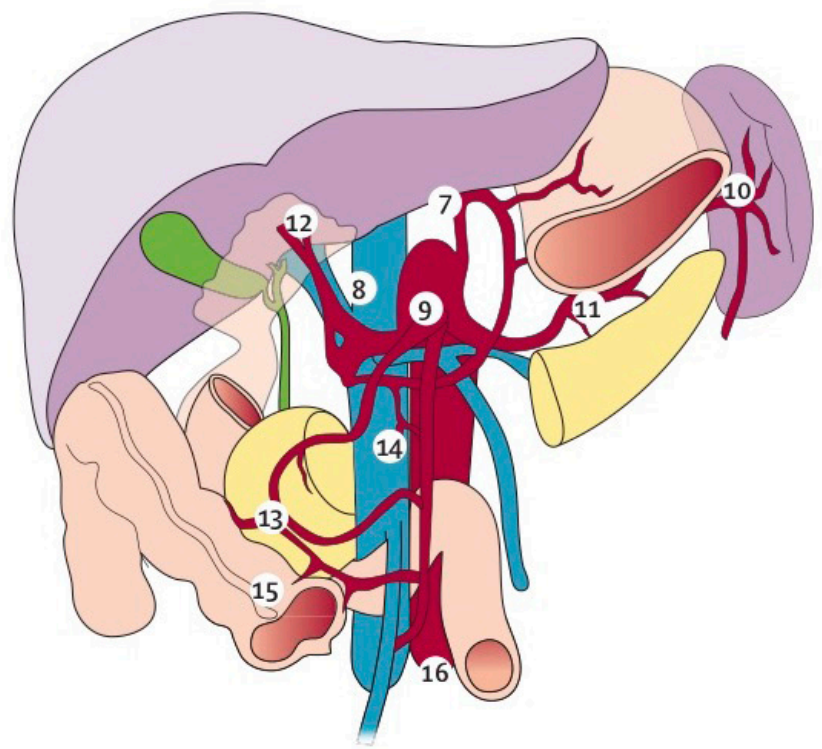

D3 Lymph nodes

12 Nodes at the hepatoduodenal ligament

13 Retropancreatic (periduodenal)nodes

14 Nodes at the root of the mesentery

15 Nodes along the middle colic vein

16 Para-aortic nodes

Figure 3 Types of lymphadenectomy for gastrectomy performed for gastric cancer by station. From Songun et al. Lancet Oncol 2010;11:439-49, with permission.

Table 1 Surgical trials investigating outcomes following lymphadenectomy with gastrectomy

\begin{tabular}{lllll}
\hline Trial name & Region & Years & Design & Findings \\
\hline MRC ST01 & UK & 1987-1994 & $\begin{array}{l}\text { Randomized to D1 or D2 } \\
\text { lymphadenectomy }\end{array}$ & $\begin{array}{l}\text { Increased hospital morbidity and mortality with D2. No difference } \\
\text { in overall survival or recurrence-free survival }\end{array}$ \\
DGCT trial & Netherlands & $1989-1993$ & $\begin{array}{l}\text { Randomized to D1 or D2 } \\
\text { lymphadenectomy }\end{array}$ & $\begin{array}{l}\text { Increased morbidity and mortality with D2. Decreased gastric } \\
\text { cancer-related death and locoregional recurrence with D2 }\end{array}$ \\
Taiwan trial & Taiwan & $1993-1999$ & $\begin{array}{l}\text { Randomized to D1 or D3 } \\
\text { lymphadenectomy }\end{array}$ & $\begin{array}{l}\text { Better 5-year survival with D3. No difference in recurrence risk in } \\
\text { subgroup analysis of R0 }\end{array}$ \\
JCOG 9501 & Japan & 1995-2001 & $\begin{array}{l}\text { Randomized to D2 or D3 } \\
\text { lymphadenectomy }\end{array}$ & $\begin{array}{l}\text { No difference in morbidity and mortality. No difference in 5-year } \\
\text { survival or recurrence-free survival }\end{array}$ \\
IGCSG-R01 & Italy & $1998-2006$ & $\begin{array}{l}\text { Randomized to D1 or D2 } \\
\text { lymphadenectomy }\end{array}$ & $\begin{array}{l}\text { No difference in morbidity and mortality. Better 5-year survival in } \\
\text { subgroup analysis of patients with positive lymph nodes after D2 }\end{array}$ \\
\hline
\end{tabular}

compared to D2 dissection (77). For adequate pathologic staging of gastric cancer patients, our institution follows the recommendation of the American Joint Committee on Cancer that a pancreas-sparing D2 lymphadenectomy should be performed with a minimum of 15 lymph nodes being retrieved at the time of gastrectomy (78).

\section{Multi-visceral resection}

For locally-advanced gastric cancer, oncologic clearance can require multi-visceral resection (MVR) to achieve negative margins. An early systematic review of 17 studies and over 1,300 patients found broad ranges for 
perioperative morbidity and mortality between 12-90\% and $0-15 \%$, respectively (79). While these ranges may raise concerns about incorporating MVR as a standard practice, it could represent a learning curve effect for extensive, challenging operations. In support of this, a 12-year Taiwanese study found that postoperative morbidity and mortality after multi-visceral resection for gastric cancer declined from $57 \%$ to $36 \%$ and $17 \%$ to $1 \%$, respectively, when comparing outcomes from the first 4 years to the last 8 years (80). A more recent multi-center Italian cohort study reported perioperative morbidity and mortality of $34 \%$ and $4 \%$, respectively (81). Recently, a multi-center US study of over 800 patients (US Gastric Cancer Collaborative) comparing outcomes following gastrectomy alone, MVR without pancreatectomy, and MVR with pancreatectomy found that although perioperative morbidity significantly increased with the extent of resection (45\%, 60\%, 59\%, respectively), perioperative morality by 90 days did not (6\%, 8\%, 9\%, respectively) (82). Five-year overall survival also significantly decreased with increased extent of resection (42\%, 28\%, 6\%, respectively) and on multivariate analysis, only MVR with pancreatectomy was an independent predictor of poor survival. In select locally advanced gastric cancer candidates demonstrating disease responsive to neoadjuvant therapy, our practice has been to offer MVR, including en bloc pancreatectomy, after extensive preoperative counselling is offered to the patient about the aforementioned results.

\section{Omental bursectomy}

Recent interest has also prompted investigation into whether omental bursectomy, or removal of the peritoneal lining over the pancreas and the anterior plane of the transverse mesocolon, yields a survival benefit over omentectomy alone with gastrectomy. A multi-center Japanese randomized controlled trial notably published in 2018 studying over 1,200 resectable patients with advanced (T3-T4) but node and metastasis negative gastric cancer reported that those undergoing bursectomy with omentectomy versus omentectomy alone had no difference in overall survival (83). Additionally, pancreatic fistulae were more common among patients undergoing bursectomy than those undergoing omentectomy alone. Two meta-analyses published thereafter corroborated this finding reporting that bursectomy was associated with no difference in the number of lymph nodes harvested, the recurrence rate, overall survival, or disease-free survival $(84,85)$.

\section{Minimally Invasive Gastrectomy}

Since first described by Kitano et al. in 1994 (86), multiple cohort studies and randomized trials have investigated outcomes associated with laparoscopic assisted gastrectomy compared to the open approach. For early gastric cancer (T1b or less) amenable to distal gastrectomy, most cohort studies have noted lower operative blood loss, less perioperative epidural and analgesic use, shorter length of stay, and no difference in or fewer postoperative complications from laparoscopic assisted distal gastrectomy compared to open distal gastrectomy (87-95). Of five randomized controlled trials comparing the two operations, three found the laparoscopic approach to be associated with less operative blood loss, two with decreased analgesic requirements, two with shorter length of stay, and three with fewer postoperative complications (96-100). Oncologically, four cohort studies found no difference in the number of lymph nodes retrieved with laparoscopic assisted distal gastrectomy compared to the open approach $(87-89,92)$, however, three found fewer lymph nodes retrieved when distal gastrectomy was approached laparoscopically $(91,93,101)$. Of the five aforementioned trials, although three found no difference in the number of lymph nodes retrieved (96-98), the two largest trials reported that the laparoscopic approach yielded significantly fewer lymph nodes $(99,100)$.

Regarding the management of patients with locally advanced gastric cancer (T2 or greater), retrospective cohort studies have also identified longer associated operative time but less blood loss, shorter length of stay, and no difference in or lower complication rate from the laparoscopic approach compared to the open analogue (102-108). In terms of oncologic outcomes, overall survival and disease-free survival were not found to be different among the laparoscopic or open approaches $(102,106,108-110)$. Lymph node retrieval among advanced gastric cancer patients undergoing laparoscopic gastrectomy has been reported to be similar to the open approach (103-109) and in fact, one study noted more lymph nodes retrieved laparoscopically than open (110). Higher quality reports comparing advanced gastric cancer patients undergoing laparoscopic versus open gastrectomy are limited. One randomized trial reported by Cai et al. in 2011 conducting a subgroup analysis of locally advanced gastric cancer patients noted that laparoscopic cases took longer but resulted in less operative blood loss and fewer incidents of postoperative pulmonary complications (111). No difference in the number of lymph nodes retrieved or mean overall survival 
were found among the laparoscopically approached patients compared to those managed with open gastrectomy.

Two ongoing trials aim to clarify the utility of laparoscopic gastrectomy over the open approach. First, the Japanese JCOG 0912 trial is designed as a non-inferiority study to compare recurrence-free survival following laparoscopic assisted distal gastrectomy compared to open distal gastrectomy for clinical stage I gastric cancer (112). Second, the Chinese CLASS-01 trial seeks to answer a similar question in a cohort of locally advanced (T2-T4a) gastric cancer patients by testing for non-inferiority with respect to 3-year disease-free survival after laparoscopic assisted gastrectomy versus open gastrectomy (113). Publication of results from these trials will inform an audience increasingly seeking strategies to enable patients to recover faster and initiate adjuvant oncologic therapy sooner (114). Newer reports have begun to focus on this outcome as more minimally invasive approaches have been found to be associated with faster return to oncologic therapy in other cancer processes $(115,116)$.

\section{Cytoreductive surgery and heated intraperitoneal chemotherapy}

Nearly $40 \%$ of newly diagnosed gastric cancer patients will present with metastatic disease, a third of whom will have peritoneal metastases (117). Development of peritoneal lesions is a common form of treatment failure that can present in up to $46 \%$ of post-gastrectomy patients (118). The peritoneal-blood barrier prevents access to these lesions with conventional systemic agents used in the adjuvant setting prompting the need for more direct therapeutic strategies $(119,120)$. Cytoreductive surgery (CRS) and hyperthermic intraperitoneal chemotherapy (HIPEC) are employed to target peritoneal metastases across a broad spectrum of oncologic diseases, including gastric cancer (Figure 4) (120). The most common agents employed in HIPEC for gastric cancer include mitomycin C, 5-fluorouracil, oxaliplatin, cisplatin, or doxorubicin. Three randomized trials have investigated outcomes associated with CRS and HIPEC in gastric cancer patients. A Japanese multi-center randomized controlled trial published by Kuramoto et al. in 2009 compared outcomes in locally advanced gastric cancer patients with intraperitoneal cancer cells without overt peritoneal metastases managed with CRS alone versus CRS and HIPEC (cisplatin) versus CRS and HIPEC and extensive intraperitoneal lavage (121). Better 5-year overall survival and fewer peritoneal recurrences were noted for patients undergoing combined CRS, HIPEC, and extensive intraperitoneal lavage compared to the other arms.. A single-center trial published by Yang et al. in 2011 studying patients with gastric carcinomatosis found a significant (although only 5 months) overall survival benefit with CRS and HIPEC using cisplatin and mitomycin C compared to CRS alone (122). Finally, a trial out of the National Institute of Health reported by Rudloff $e t$ al. in 2014 of patients with gastric carcinomatosis found that those treated with CRS, HIPEC (oxaliplatin), and systemic FOLFIRINOX had better survival (albeit 7 months) over the control arm treated with systemic FOLFIRINOX alone (123). The ongoing PERISCOPE II trial will build on this work by investigating whether gastric cancer patients with limited peritoneal dissemination and/or positive peritoneal cytology managed with systemic chemotherapy, gastrectomy, CRS and HIPEC have a survival benefit over those managed with palliative systemic chemotherapy alone (124). As more work is done investigating outcomes in gastric cancer patients treated for peritoneal metastases, better patient selection for these advanced therapies will be possible.

\section{Conclusions}

Selection of the appropriate surgical strategy depends on the epicenter and extent of the gastroesophageal or gastric cancer. Siewert class I tumors should be treated with either transthoracic or transhiatal esophagectomy. The former approach is associated with a more extensive and precise mediastinal nodal dissection at the expense of increased morbidity. However, both approaches have equivalent longterm survival. Siewert II tumors can metastasize to both abdominal and mediastinal lymph nodes, so the resection strategy (esophagectomy or total gastrectomy with resection of the distal esophagus) should involve dissection of paracardial, lesser curvature, left gastric and lower thoracic paraesophageal nodes. Siewert III tumors can be treated with either proximal or total gastrectomy. Total gastrectomy provides higher lymph node counts and lower rates of anastomotic stricture and reflux esophagitis. For early midstomach tumors, the option of pylorus preservation can mitigate the risk for alkaline reflux following reconstruction after gastrectomy. Locally advanced, extensive, or genetically-driven gastric cancers, however, should be managed with total gastrectomy to offer the greatest oncologic benefit. Experience with minimally invasive options for gastrectomy and esophagectomy are expanding 

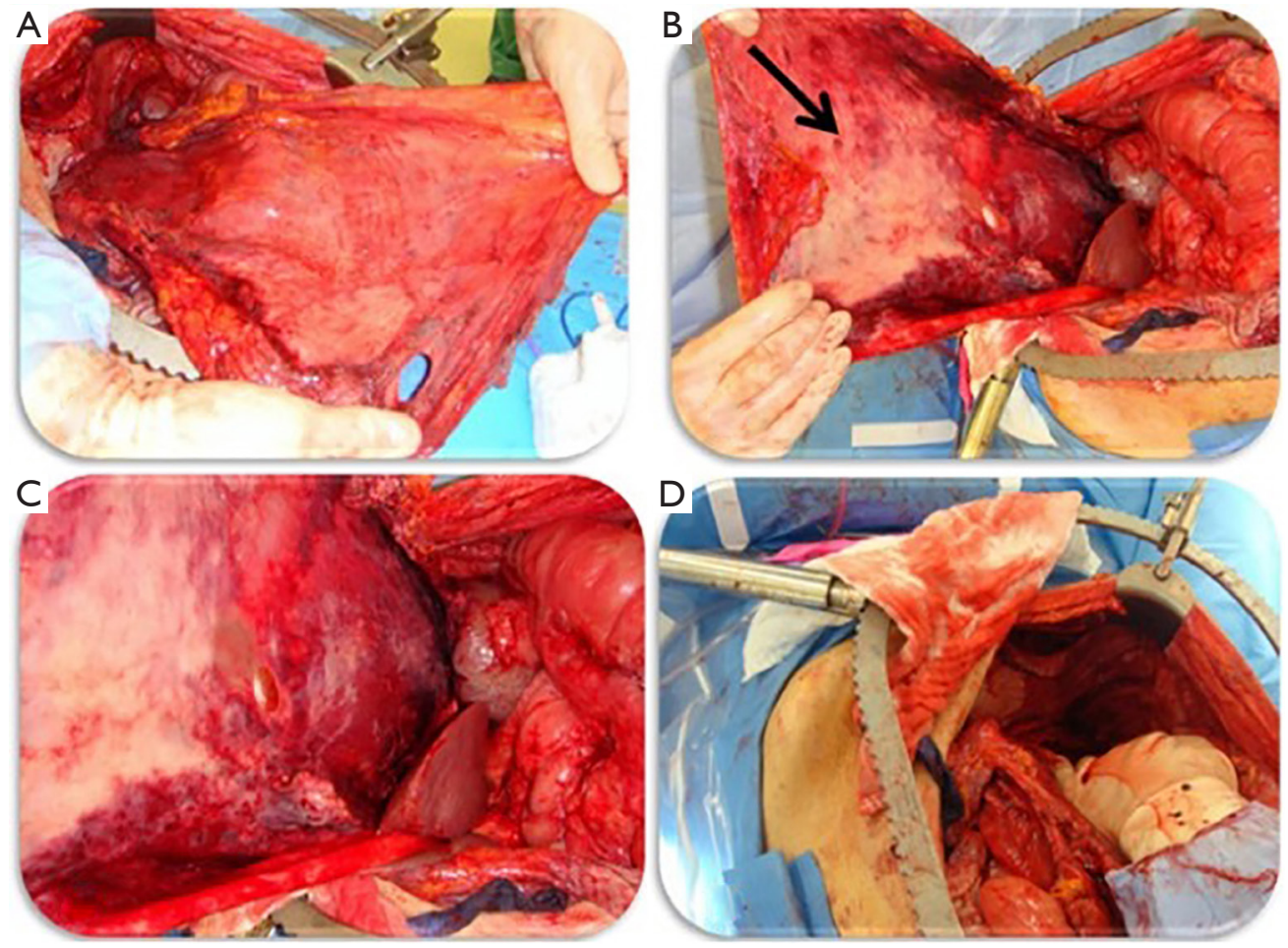

Figure 4 Radical peritonectomy of the left upper quadrant. (A) The non-visceral view as the parietal peritoneum is stripped from the left diaphragm, left paracolic gutter, and the left upper abdominal wall extending to the left lower extremity of the patient. The falciform ligament and the attached pre-peritoneal fat is removed en bloc with the specimen. (B) The visceral view as the peritoneum is stripped. The arrow marks disease along the peritoneal surface. (C) Magnified appearance of peritoneal disease. (D) The left upper quadrant after radical peritonectomy. From Rudloff et al., J Surg Oncol 2014;110:275-84, with permission.

and will likely become more prevalent as strategies returning patients sooner to their intended oncologic management are sought after. At the time of gastrectomy, the optimal lymph node dissection should include a D2 lymphadenectomy over D1 lymphadenectomy given recent updated reports describing better long-term benefit. For more extensive disease, select surgical candidates can benefit from multivisceral resection or cytoreduction with intraperitoneal chemotherapy. Perioperative combination chemotherapy or neoadjuvant chemoradiation is the mainstay of treatment for the majority of upfront unresectable patients.

\section{Acknowledgments}

Funding: None.

\section{Footnote}

Provenance and Peer Review: This article was commissioned by the Guest Editor (Jaffer A. Ajani) for the series "Gastrointestinal Cancer" published in Translational Gastroenterology and Hepatology. The article was sent for external peer review organized by the Guest Editor and the editorial office.

Conflicts of Interest: Both authors have completed the ICMJE uniform disclosure form (available at http://dx.doi. org/10.21037/tgh.2020.02.06). The series "Gastrointestinal Cancer" was commissioned by the editorial office without any funding or sponsorship. The authors have no other conflicts of interest to declare.

Ethical Statement: The authors are accountable for all aspects of the work in ensuring that questions related to the accuracy or integrity of any part of the work are appropriately investigated and resolved.

Open Access Statement: This is an Open Access article 
distributed in accordance with the Creative Commons Attribution-NonCommercial-NoDerivs 4.0 International License (CC BY-NC-ND 4.0), which permits the noncommercial replication and distribution of the article with the strict proviso that no changes or edits are made and the original work is properly cited (including links to both the formal publication through the relevant DOI and the license). See: https://creativecommons.org/licenses/by-ncnd/4.0/.

\section{References}

1. Siegel RL, Miller KD, Jemal A. Cancer statistics, 2019. CA Cancer J Clin 2019;69:7-34.

2. Groh EM, Gupta S, Brown ZJ, et al. Staging Laparoscopy is Underutilized in the Management of Gastric Adenocarcinoma. Ann Surg Oncol 2020;27:1473-9.

3. Mezhir JJ, Shah MA, Jacks LM, et al. Positive peritoneal cytology in patients with gastric cancer: natural history and outcome of 291 patients. Ann Surg Oncol 2010;17:3173-80.

4. Ramos RF, Scalon FM, Scalon MM, et al. Staging laparoscopy in gastric cancer to detect peritoneal metastases: A systematic review and meta-analysis. Eur J Surg Oncol 2016;42:1315-21.

5. Allen CJ, Newhook TE, Vreeland TJ, et al. Yield of peritoneal cytology in staging patients with gastric and gastroesophageal cancer. J Surg Oncol 2019;120:1350-7.

6. Brenkman HJF, Gertsen EC, Vegt E, et al. Evaluation of PET and laparoscopy in STagIng advanced gastric cancer: a multicenter prospective study (PLASTIC-study). BMC Cancer 2018;18:450.

7. Li Z, Li Z, Zhang L, et al. Staging laparoscopy for locally advanced gastric cancer in Chinese patients: a multicenter prospective registry study. BMC Cancer 2018;18:63.

8. Rudiger Siewert J, Feith M, Werner M, et al. Adenocarcinoma of the esophagogastric junction: results of surgical therapy based on anatomical/topographic classification in 1,002 consecutive patients. Ann Surg 2000;232:353-61.

9. Mazer LM, Poultsides GA. What Is the Best Operation for Proximal Gastric Cancer and Distal Esophageal Cancer? Surg Clin North Am 2019;99:457-69.

10. Rice TW, Gress DM, Patil DT, et al. Cancer of the esophagus and esophagogastric junction-Major changes in the American Joint Committee on Cancer eighth edition cancer staging manual. CA Cancer J Clin 2017;67:304-17.

11. Hasegawa S, Yoshikawa T, Rino Y, et al. Priority of lymph node dissection for Siewert type II/III adenocarcinoma of the esophagogastric junction. Ann Surg Oncol 2013;20:4252-9.

12. Hulscher JB, van Sandick JW, de Boer AG, et al. Extended transthoracic resection compared with limited transhiatal resection for adenocarcinoma of the esophagus. N Engl J Med 2002;347:1662-9.

13. Orringer MB, Marshall B, Iannettoni MD. Transhiatal esophagectomy: clinical experience and refinements. Ann Surg 1999;230:392-400; discussion 403.

14. Haverkamp L, Ruurda JP, van Leeuwen MS, et al. Systematic review of the surgical strategies of adenocarcinomas of the gastroesophageal junction. Surg Oncol 2014;23:222-8.

15. Hulscher JB, Tijssen JG, Obertop H, et al. Transthoracic versus transhiatal resection for carcinoma of the esophagus: a meta-analysis. Ann Thorac Surg 2001;72:306-13.

16. Boshier PR, Anderson O, Hanna GB. Transthoracic versus transhiatal esophagectomy for the treatment of esophagogastric cancer: a meta-analysis. Ann Surg 2011;254:894-906.

17. van der Sluis PC, Ruurda JP, van der Horst S, et al. Robot-assisted minimally invasive thoraco-laparoscopic esophagectomy versus open transthoracic esophagectomy for resectable esophageal cancer, a randomized controlled trial (ROBOT trial). Trials 2012;13:230.

18. Di Leo A, Zanoni A. Siewert III adenocarcinoma: treatment update. Updates Surg 2017;69:319-25.

19. Papachristou DN, Fortner JG. Adenocarcinoma of the gastric cardia. The choice of gastrectomy. Ann Surg 1980;192:58-64.

20. Nomura E, Okajima K. Function-preserving gastrectomy for gastric cancer in Japan. World J Gastroenterol 2016;22:5888-95.

21. Takiguchi N, Takahashi M, Ikeda M, et al. Long-term quality-of-life comparison of total gastrectomy and proximal gastrectomy by postgastrectomy syndrome assessment scale (PGSAS-45): a nationwide multiinstitutional study. Gastric Cancer 2015;18:407-16.

22. Wen L, Chen XZ, Wu B, et al. Total vs. proximal gastrectomy for proximal gastric cancer: a systematic review and meta-analysis. Hepatogastroenterology 2012;59:633-40.

23. Rosa F, Quero G, Fiorillo C, et al. Total vs proximal gastrectomy for adenocarcinoma of the upper third of the stomach: a propensity-score-matched analysis of a multicenter western experience (On behalf of the Italian Research Group for Gastric Cancer-GIRCG). Gastric Cancer 2018;21:845-52. 
24. Xiao JW, Liu ZL, Ye PC, et al. Clinical comparison of antrum-preserving double tract reconstruction vs rouxen-Y reconstruction after gastrectomy for Siewert types II and III adenocarcinoma of the esophagogastric junction. World J Gastroenterol 2015;21:9999-10007.

25. Sugoor P, Shah S, Dusane R, et al. Proximal gastrectomy versus total gastrectomy for proximal third gastric cancer: total gastrectomy is not always necessary. Langenbecks Arch Surg 2016;401:687-97.

26. Ito H, Clancy TE, Osteen RT, et al. Adenocarcinoma of the gastric cardia: what is the optimal surgical approach? J Am Coll Surg 2004;199:880-6.

27. Barbour AP, Rizk NP, Gonen M, et al. Adenocarcinoma of the gastroesophageal junction: influence of esophageal resection margin and operative approach on outcome. Ann Surg 2007;246:1-8.

28. Kauppila JH, Wahlin K, Lagergren J. Gastrectomy compared to oesophagectomy for Siewert II and III gastro-oesophageal junctional cancer in relation to resection margins, lymphadenectomy and survival. Sci Rep 2017;7:17783.

29. Postlewait LM, Squires MH, 3rd, Kooby DA, et al. The importance of the proximal resection margin distance for proximal gastric adenocarcinoma: A multi-institutional study of the US Gastric Cancer Collaborative. J Surg Oncol 2015;112:203-7.

30. Omloo JM, Lagarde SM, Hulscher JB, et al. Extended transthoracic resection compared with limited transhiatal resection for adenocarcinoma of the mid/distal esophagus: five-year survival of a randomized clinical trial. Ann Surg 2007;246:992-1000; discussion 1001.

31. Lai S, Su T, He X, et al. Prognostic value of resected lymph nodes numbers for Siewert II gastroesophageal junction cancer. Oncotarget 2018;9:2797-809.

32. Makris EA, Poultsides GA. Surgical Considerations in the Management of Gastric Adenocarcinoma. Surg Clin North Am 2017;97:295-316.

33. Kunisaki C, Shimada H, Nomura M, et al. Therapeutic strategy for signet ring cell carcinoma of the stomach. Br J Surg 2004;91:1319-24.

34. Bardram L, Hansen TV, Gerdes AM, et al. Prophylactic total gastrectomy in hereditary diffuse gastric cancer: identification of two novel CDH1 gene mutations-a clinical observational study. Fam Cancer 2014;13:231-42.

35. Kim J, Lee J, Hyung WJ, et al. Gastric cancer surgery without drains: a prospective randomized trial. J Gastrointest Surg 2004;8:727-32.

36. Alvarez Uslar R, Molina H, Torres O, et al. Total gastrectomy with or without abdominal drains. A prospective randomized trial. Rev Esp Enferm Dig 2005;97:562-9.

37. Kumar M, Yang SB, Jaiswal VK, et al. Is prophylactic placement of drains necessary after subtotal gastrectomy? World J Gastroenterol 2007;13:3738-41.

38. Liu HP, Zhang YC, Zhang YL, et al. Drain versus nodrain after gastrectomy for patients with advanced gastric cancer: systematic review and meta-analysis. Dig Surg 2011;28:178-89.

39. Wang Z, Chen J, Su K, et al. Abdominal drainage versus no drainage post-gastrectomy for gastric cancer. Cochrane Database Syst Rev 2015:CD008788.

40. Dann GC, Squires MH 3rd, Postlewait LM, et al. Value of Peritoneal Drain Placement After Total Gastrectomy for Gastric Adenocarcinoma: A Multi-institutional Analysis from the US Gastric Cancer Collaborative. Ann Surg Oncol 2015;22 Suppl 3:S888-97.

41. Dann GC, Squires MH 3rd, Postlewait LM, et al. An assessment of feeding jejunostomy tube placement at the time of resection for gastric adenocarcinoma: A seveninstitution analysis of 837 patients from the U.S. gastric cancer collaborative. J Surg Oncol 2015;112:195-202.

42. Sun Z, Shenoi MM, Nussbaum DP, et al. Feeding jejunostomy tube placement during resection of gastric cancers. J Surg Res 2016;200:189-94.

43. Gustavsson S, Ilstrup DM, Morrison P, et al. Roux-Y stasis syndrome after gastrectomy. Am J Surg 1988;155:490-4.

44. Burden WR, Hodges RP, Hsu M, et al. Alkaline reflux gastritis. Surg Clin North Am 1991;71:33-44.

45. El Halabi HM, Lawrence W Jr. Clinical results of various reconstructions employed after total gastrectomy. J Surg Oncol 2008;97:186-92.

46. Csendes A, Burgos AM, Smok G, et al. Latest results (1221 years) of a prospective randomized study comparing Billroth II and Roux-en-Y anastomosis after a partial gastrectomy plus vagotomy in patients with duodenal ulcers. Ann Surg 2009;249:189-94.

47. Zong L, Chen P. Billroth I vs. Billroth II vs. Roux-en-Y following distal gastrectomy: a meta-analysis based on 15 studies. Hepatogastroenterology 2011;58:1413-24.

48. Hirao M, Takiguchi S, Imamura H, et al. Comparison of Billroth I and Roux-en-Y reconstruction after distal gastrectomy for gastric cancer: one-year postoperative effects assessed by a multi-institutional RCT. Ann Surg Oncol 2013;20:1591-7.

49. Eagon JC, Miedema BW, Kelly KA. Postgastrectomy syndromes. Surg Clin North Am 1992;72:445-65. 
50. Isozaki $\mathrm{H}$, Okajima $\mathrm{K}$, Momura $\mathrm{E}$, et al. Postoperative evaluation of pylorus-preserving gastrectomy for early gastric cancer. Br J Surg 1996;83:266-9.

51. Imada T, Rino Y, Takahashi M, et al. Postoperative functional evaluation of pylorus-preserving gastrectomy for early gastric cancer compared with conventional distal gastrectomy. Surgery 1998;123:165-70.

52. Oh SY, Lee HJ, Yang HK. Pylorus-Preserving Gastrectomy for Gastric Cancer. J Gastric Cancer 2016;16:63-71.

53. Kong SH, Kim JW, Lee HJ, et al. The safety of the dissection of lymph node stations 5 and 6 in pyloruspreserving gastrectomy. Ann Surg Oncol 2009;16:3252-8.

54. Japanese Gastric Cancer Association. Japanese gastric cancer treatment guidelines 2014 (ver. 4). Gastric Cancer 2017;20:1-19.

55. Ajani JA, D'Amico TA, Almhanna K, et al. Gastric Cancer, Version 3.2016, NCCN Clinical Practice Guidelines in Oncology. J Natl Compr Canc Netw 2016;14:1286-312.

56. Ushimaru Y, Fujiwara Y, Shishido Y, et al. Clinical Outcomes of Gastric Cancer Patients Who Underwent Proximal or Total Gastrectomy: A Propensity ScoreMatched Analysis. World J Surg 2018;42:1477-84.

57. Xu Y, Tan Y, Wang Y, et al. Proximal versus total gastrectomy for proximal early gastric cancer: A systematic review and meta-analysis. Medicine (Baltimore) 2019;98:e15663.

58. Kumagai K, Shimizu K, Yokoyama N, et al. Questionnaire survey regarding the current status and controversial issues concerning reconstruction after gastrectomy in Japan. Surg Today 2012;42:411-8.

59. Wang S, Lin S, Wang H, et al. Reconstruction methods after radical proximal gastrectomy: A systematic review. Medicine (Baltimore) 2018;97:e0121.

60. Nakamura M, Yamaue H. Reconstruction after proximal gastrectomy for gastric cancer in the upper third of the stomach: a review of the literature published from 2000 to 2014. Surg Today 2016;46:517-27.

61. Siewert JR, Bottcher K, Stein HJ, et al. Relevant prognostic factors in gastric cancer: ten-year results of the German Gastric Cancer Study. Ann Surg 1998;228:449-61.

62. Lee HK, Yang HK, Kim WH, et al. Influence of the number of lymph nodes examined on staging of gastric cancer. Br J Surg 2001;88:1408-12.

63. Bouvier AM, Haas O, Piard F, et al. How many nodes must be examined to accurately stage gastric carcinomas? Results from a population based study. Cancer 2002;94:2862-6.

64. Smith DD, Schwarz RR, Schwarz RE. Impact of total lymph node count on staging and survival after gastrectomy for gastric cancer: data from a large USpopulation database. J Clin Oncol 2005;23:7114-24.

65. Gholami S, Janson L, Worhunsky DJ, et al. Number of Lymph Nodes Removed and Survival after Gastric Cancer Resection: An Analysis from the US Gastric Cancer Collaborative. J Am Coll Surg 2015;221:291-9.

66. Bonenkamp JJ, Songun I, Hermans J, et al. Randomised comparison of morbidity after D1 and D2 dissection for gastric cancer in 996 Dutch patients. Lancet 1995;345:745-8.

67. Cuschieri A, Fayers P, Fielding J, et al. Postoperative morbidity and mortality after D1 and D2 resections for gastric cancer: preliminary results of the MRC randomised controlled surgical trial. The Surgical Cooperative Group. Lancet 1996;347:995-9.

68. Cuschieri A, Weeden S, Fielding J, et al. Patient survival after D1 and D2 resections for gastric cancer: long-term results of the MRC randomized surgical trial. Surgical Cooperative Group. Br J Cancer 1999;79:1522-30.

69. Songun I, Putter H, Kranenbarg EM, et al. Surgical treatment of gastric cancer: 15-year follow-up results of the randomised nationwide Dutch D1D2 trial. Lancet Oncol 2010;11:439-49.

70. Degiuli M, Sasako M, Ponti A, et al. Morbidity and mortality in the Italian Gastric Cancer Study Group randomized clinical trial of D1 versus D2 resection for gastric cancer. Br J Surg 2010;97:643-9.

71. Degiuli M, Sasako M, Ponti A, et al. Randomized clinical trial comparing survival after D1 or D2 gastrectomy for gastric cancer. Br J Surg 2014;101:23-31.

72. Maruyama K, Okabayashi K, Kinoshita T. Progress in gastric cancer surgery in Japan and its limits of radicality. World J Surg 1987;11:418-25.

73. Bonenkamp JJ, Hermans J, Sasako M, et al. Extended lymph-node dissection for gastric cancer. N Engl J Med 1999;340:908-14.

74. Hartgrink HH, van de Velde CJ, Putter H, et al. Extended lymph node dissection for gastric cancer: who may benefit? Final results of the randomized Dutch gastric cancer group trial. J Clin Oncol 2004;22:2069-77.

75. Maruyama K, Sasako M, Kinoshita T, et al. Pancreaspreserving total gastrectomy for proximal gastric cancer. World J Surg 1995;19:532-6.

76. Wu CW, Hsiung CA, Lo SS, et al. Randomized clinical trial of morbidity after D1 and D3 surgery for gastric cancer. Br J Surg 2004;91:283-7.

77. Sasako M, Sano T, Yamamoto S, et al. D2 lymphadenectomy 
alone or with para-aortic nodal dissection for gastric cancer. N Engl J Med 2008;359:453-62.

78. Ajani JA, In H, Sano T, et al. AJCC Cancer Staging Atlas. In: Amin MB, Edge SB, Greene FL, editors. AJCC Cancer Staging Atlas. 8 ed. Chicago, IL: Springer; 2017. p. 203-22.

79. Brar SS, Seevaratnam R, Cardoso R, et al. Multivisceral resection for gastric cancer: a systematic review. Gastric Cancer 2012;15 Suppl 1:S100-7.

80. Lo SS, Wu CW, Shen KH, et al. Higher morbidity and mortality after combined total gastrectomy and pancreaticosplenectomy for gastric cancer. World J Surg 2002;26:678-82.

81. Pacelli F, Cusumano G, Rosa F, et al. Multivisceral resection for locally advanced gastric cancer: an Italian multicenter observational study. JAMA Surg 2013;148:353-60.

82. Tran TB, Worhunsky DJ, Norton JA, et al. Multivisceral Resection for Gastric Cancer: Results from the US Gastric Cancer Collaborative. Ann Surg Oncol 2015;22 Suppl $3: \mathrm{S} 840-7$.

83. Kurokawa Y, Doki Y, Mizusawa J, et al. Bursectomy versus omentectomy alone for resectable gastric cancer (JCOG1001): a phase 3, open-label, randomised controlled trial. Lancet Gastroenterol Hepatol 2018;3:460-8.

84. Nie RC, Yuan SQ, Chen S, et al. Bursectomy for advanced gastric cancer: an update meta-analysis. World J Surg Oncol 2018;16:66.

85. Xiong B, Ma L, Huang W, et al. Efficiency of bursectomy in patients with resectable gastric cancer: An updated meta-analysis. Eur J Surg Oncol 2019;45:1483-92.

86. Kitano S, Iso Y, Moriyama M, et al. Laparoscopyassisted Billroth I gastrectomy. Surg Laparosc Endosc 1994;4:146-8.

87. Adachi Y, Shiraishi N, Shiromizu A, et al. Laparoscopyassisted Billroth I gastrectomy compared with conventional open gastrectomy. Arch Surg 2000;135:806-10.

88. Yano H, Monden T, Kinuta M, et al. The usefulness of laparoscopy-assisted distal gastrectomy in comparison with that of open distal gastrectomy for early gastric cancer. Gastric Cancer 2001;4:93-7.

89. Kim MC, $\mathrm{Kim} \mathrm{KH}, \mathrm{Kim} \mathrm{HH}$, et al. Comparison of laparoscopy-assisted by conventional open distal gastrectomy and extraperigastric lymph node dissection in early gastric cancer. J Surg Oncol 2005;91:90-4.

90. Mochiki E, Kamiyama Y, Aihara R, et al. Laparoscopic assisted distal gastrectomy for early gastric cancer: Five years' experience. Surgery 2005;137:317-22.

91. Lee SI, Choi YS, Park DJ, et al. Comparative study of laparoscopy-assisted distal gastrectomy and open distal gastrectomy. J Am Coll Surg 2006;202:874-80.

92. Kawamura H, Homma S, Yokota R, et al. Inspection of safety and accuracy of D2 lymph node dissection in laparoscopy-assisted distal gastrectomy. World J Surg 2008;32:2366-70.

93. Kiyama T, Fujita I, Kanno H, et al. Laparoscopy-assisted distal gastrectomy for gastric cancer. J Gastrointest Surg 2008;12:1807-11.

94. Lee JH, Yom CK, Han HS. Comparison of long-term outcomes of laparoscopy-assisted and open distal gastrectomy for early gastric cancer. Surg Endosc 2009;23:1759-63.

95. Lee JH, Park DJ, Kim HH, et al. Comparison of complications after laparoscopy-assisted distal gastrectomy and open distal gastrectomy for gastric cancer using the Clavien-Dindo classification. Surg Endosc 2012;26:1287-95.

96. Kitano S, Shiraishi N, Fujii K, et al. A randomized controlled trial comparing open vs laparoscopy-assisted distal gastrectomy for the treatment of early gastric cancer: an interim report. Surgery 2002;131:S306-11.

97. Lee JH, Han HS, Lee JH. A prospective randomized study comparing open vs laparoscopy-assisted distal gastrectomy in early gastric cancer: early results. Surg Endosc 2005;19:168-73.

98. Hayashi H, Ochiai T, Shimada H, et al. Prospective randomized study of open versus laparoscopy-assisted distal gastrectomy with extraperigastric lymph node dissection for early gastric cancer. Surg Endosc 2005;19:1172-6.

99. Kim YW, Baik YH, Yun YH, et al. Improved quality of life outcomes after laparoscopy-assisted distal gastrectomy for early gastric cancer: results of a prospective randomized clinical trial. Ann Surg 2008;248:721-7.

100. Kim W, Kim HH, Han SU, et al. Decreased Morbidity of Laparoscopic Distal Gastrectomy Compared With Open Distal Gastrectomy for Stage I Gastric Cancer: Short-term Outcomes From a Multicenter Randomized Controlled Trial (KLASS-01). Ann Surg 2016;263:28-35.

101. Shimizu S, Uchiyama A, Mizumoto K, et al. Laparoscopically assisted distal gastrectomy for early gastric cancer: is it superior to open surgery? Surg Endosc 2000;14:27-31.

102.Hur H, Jeon HM, Kim W. Laparoscopy-assisted distal gastrectomy with D2 lymphadenectomy for T2b advanced gastric cancers: three years' experience. J Surg Oncol 2008;98:515-9.

103. Du XH, Li R, Chen L, et al. Laparoscopy-assisted D2 radical distal gastrectomy for advanced gastric cancer: 
initial experience. Chin Med J (Engl) 2009;122:1404-7.

104. Guzman EA, Pigazzi A, Lee B, et al. Totally laparoscopic gastric resection with extended lymphadenectomy for gastric adenocarcinoma. Ann Surg Oncol 2009;16:2218-23.

105.Hwang SI, Kim HO, Yoo CH, et al. Laparoscopic-assisted distal gastrectomy versus open distal gastrectomy for advanced gastric cancer. Surg Endosc 2009;23:1252-8.

106.Zhao Y, Yu P, Hao Y, et al. Comparison of outcomes for laparoscopically assisted and open radical distal gastrectomy with lymphadenectomy for advanced gastric cancer. Surg Endosc 2011;25:2960-6.

107. Kim KH, Kim MC, Jung GJ, et al. Comparative analysis of five-year survival results of laparoscopy-assisted gastrectomy versus open gastrectomy for advanced gastric cancer: a case-control study using a propensity score method. Dig Surg 2012;29:165-71.

108. Bo T, Peiwu Y, Feng Q, et al. Laparoscopy-assisted vs. open total gastrectomy for advanced gastric cancer: longterm outcomes and technical aspects of a case-control study. J Gastrointest Surg 2013;17:1202-8.

109. Chen QY, Huang CM, Lin JX, et al. Laparoscopy-assisted versus open D2 radical gastrectomy for advanced gastric cancer without serosal invasion: a case control study. World J Surg Oncol 2012;10:248.

110. Hamabe A, Omori T, Tanaka K, et al. Comparison of longterm results between laparoscopy-assisted gastrectomy and open gastrectomy with D2 lymph node dissection for advanced gastric cancer. Surg Endosc 2012;26:1702-9.

111. Cai J, Wei D, Gao CF, et al. A prospective randomized study comparing open versus laparoscopy-assisted D2 radical gastrectomy in advanced gastric cancer. Dig Surg 2011;28:331-7.

112. Katai H, Mizusawa J, Katayama H, et al. Survival outcomes after laparoscopy-assisted distal gastrectomy versus open distal gastrectomy with nodal dissection for clinical stage IA or IB gastric cancer (JCOG0912): a multicentre, noninferiority, phase 3 randomised controlled trial. Lancet Gastroenterol Hepatol 2020;5:142-51.

113. Yu J, Huang C, Sun Y, et al. Effect of Laparoscopic vs Open Distal Gastrectomy on 3-Year Disease-Free Survival in Patients With Locally Advanced Gastric Cancer: The CLASS-01 Randomized Clinical Trial. JAMA 2019;321:1983-92.

114.Kim BJ, Caudle AS, Gottumukkala V, et al. The Impact of Postoperative Complications on a Timely Return to Intended Oncologic Therapy (RIOT): the Role of Enhanced Recovery in the Cancer Journey. Int Anesthesiol Clin 2016;54:e33-46.
115.Aloia TA, Zimmitti G, Conrad C, et al. Return to intended oncologic treatment (RIOT): a novel metric for evaluating the quality of oncosurgical therapy for malignancy. J Surg Oncol 2014;110:107-14.

116.Lillemoe HA, Marcus RK, Kim BJ, et al. Detours on the Road to Recovery: What Factors Delay Readiness to Return to Intended Oncologic Therapy (RIOT) After Liver Resection for Malignancy? J Gastrointest Surg 2019;23:2362-71.

117. Thomassen I, van Gestel YR, van Ramshorst B, et al. Peritoneal carcinomatosis of gastric origin: a populationbased study on incidence, survival and risk factors. Int J Cancer 2014;134:622-8.

118. Yoo CH, Noh SH, Shin DW, et al. Recurrence following curative resection for gastric carcinoma. Br J Surg 2000;87:236-42.

119. Hasovits C, Clarke S. Pharmacokinetics and pharmacodynamics of intraperitoneal cancer chemotherapeutics. Clin Pharmacokinet 2012;51:203-24.

120. Guner A, Yildirim R. Surgical management of metastatic gastric cancer: moving beyond the guidelines. Transl Gastroenterol Hepatol 2019;4:58.

121. Kuramoto M, Shimada S, Ikeshima S, et al. Extensive intraoperative peritoneal lavage as a standard prophylactic strategy for peritoneal recurrence in patients with gastric carcinoma. Ann Surg 2009;250:242-6.

122. Yang XJ, Huang CQ, Suo T, et al. Cytoreductive surgery and hyperthermic intraperitoneal chemotherapy improves survival of patients with peritoneal carcinomatosis from gastric cancer: final results of a phase III randomized clinical trial. Ann Surg Oncol 2011;18:1575-81.

123. Rudloff U, Langan RC, Mullinax JE, et al. Impact of maximal cytoreductive surgery plus regional heated intraperitoneal chemotherapy (HIPEC) on outcome of patients with peritoneal carcinomatosis of gastric origin: results of the GYMSSA trial. J Surg Oncol 2014;110:275-84.

124. Koemans WJ, van der Kaaij RT, Boot H, et al. Cytoreductive surgery and hyperthermic intraperitoneal chemotherapy versus palliative systemic chemotherapy in stomach cancer patients with peritoneal dissemination, the study protocol of a multicentre randomised controlled trial (PERISCOPE II). BMC Cancer 2019;19:420.

doi: $10.21037 / \operatorname{tgh} .2020 .02 .06$

Cite this article as: Narayan RR, Poultsides GA. Advances in the surgical management of gastric and gastroesophageal junction cancer. Transl Gastroenterol Hepatol 2021;6:16. 